\title{
CONTRIBUIÇÕES DA HISTÓRIA DOS CONCEITOS (BEGRIFFSGESCHICHTE) PARA OS ESTUDOS ORGANIZACIONAIS
}

\author{
Fabio Vizeu1 \\ Queila Regina Souza Matitz ${ }^{2}$
}

\section{Resumo}

O presente trabalho pretendeu ensaiar possíveis contribuições para os estudos organizacionais do método historiográfico denominado por 'história dos conceitos' (Begriffsgeschichte), de autoria do historiador alemão Reinhart Koselleck. Assumindo uma dimensão maior do que a pura implicação metodológica da escrita historiográfica, a Begriffsgeschichte deve ser compreendida como uma teoria da história (JASMIN, 2006; WHITE, 2002) que, além de situar o que se trata de fato a natureza daquilo que denominamos por 'História', também nos permite avançar na análise da própria modernidade. Diante destes aspectos, podemos demarcar a contribuição que se pretende com a adoção da perspectiva da História dos Conceitos para os estudos organizacionais. Epistemologicamente, consideramos a significativa contribuição teórica da abordagem de Koselleck, já que a teoria da história implícita na Begriffsgeschichte serve como arcabouço explicativo para a análise do fenômeno organizacional enquanto um dos mais importantes produtos históricos da modernidade. Por fim, em termos metodológicos, a Begriffsgeschichte oferece recursos para se operacionalizar pesquisas que verifiquem a real dimensão de formas discursivas específicas dentro do pensamento organizacional, formas estas que se traduzem nos conceitos fundamentais da prática organizacional e na reflexão que os acadêmicos fazem desta.

Palavras-Chave: História dos Conceitos; Koselleck; Estudos Organizacionais

\section{Contributions of Conceptual History (Begriffsgeschichte) for Organization Studies}

\footnotetext{
Abstract

${ }^{1}$ Professor do Programa de Mestrado e Doutorado em Administração da Universidade Positivo e Pesquisador do IBEPES.

${ }^{2}$ Professora classe Adjunto I na UFPR e coordenadora de tutoria do curso de especialização em Gestão Pública da UAB/PNAP/UFPR

Revista Brasileira de Estudos Organizacionais • v. 1. n. 2, p. 165-186, dez. 2014, eISSN: 2447-4851

Sociedade Brasileira de Estudos Organizacionais
} 
This study intended to verify possible contributions of Reinhart Koselleck's Conceptual History (Begriffsgeschichte) to Organization Studies. Assuming a larger than pure methodological implication of historian writing, Begriffsgeschichte must be understood as a theory of History (JASMIN, 2006; WHITE, 2002). In addition, it helps to situate the nature of History itself, but also, it allows us to move forward in the analysis of Modernity. In this sense, we can delimitate the main contributions of Conceptual History to organizational studies. First, it can enlighten about Epistemology, since Begriffsgeschichte serves as an explanatory framework for the analysis of organizational phenomenon as one of the most important historical products of modernity. Second, in terms of methodology, the Begriffsgeschichte offers instrumental resources to organizational research. In doing so, it clarify how specific discursive forms within the organizational thought can translate the fundamental concepts of organizational practice.

Keywords: Conceptual History; Koselleck; Organization Studies

\section{Aportes de la Historia de Conceptos (Begriffsgeschichte) para Estudios Organizacionales}

\section{Resumen}

Este estudio pretende verificar las posibles contribuciones de la historia conceptual de Reinhart Koselleck (Begriffsgeschichte) para Estudios Organizacionales. Suponiendo una más grande que la implicación metodológica pura de la escritura historiador, Begriffsgeschichte debe ser entendida como una teoría de la Historia (JASMIN, 2006; BLANCO, 2002). Además, ayuda a situar a la naturaleza de la historia misma, sino también, nos permite avanzar en el análisis de la Modernidad. En este sentido, podemos delimitar las principales aportaciones de la historia conceptual de los estudios organizacionales. En primer lugar, puede iluminar sobre Epistemología, ya Begriffsgeschichte sirve como un marco explicativo para el análisis del fenómeno organizacional como uno de los productos históricos más importantes de la modernidad. En segundo lugar, en cuanto a la metodología, el Begriffsgeschichte ofrece recursos instrumentales para la investigación de la organización. Al hacerlo, es aclarar cómo las formas discursivas específicas dentro del pensamiento organizacional pueden traducir los conceptos fundamentales de la práctica de la organización.

Palabras Clave: Historia de Conceptos; Koselleck; Estudios Organizacionales. 


\section{Introdução}

A defesa por mais história nos estudos organizacionais brasileiros não é uma questão nova, tendo em conta o já percebido engajamento de certos pesquisadores em assinalar essa problemática dentro da reflexão sobre a produção acadêmica neste campo. Neste ponto, podemos afirmar que o alerta feito por alguns pesquisadores da área sobre a necessidade de tratar seriamente a história nas pesquisas sobre organizações (BOOTH; ROWLINSON, 2006; VIZEU, 2007; COSTA, BARROS; MARTINS, 2009) já está sendo adotado pela academia, haja vista, só para citar um exemplo, a criação de uma linha temática exclusiva para submissão de trabalhos relacionados à história e memória em estudos organizacionais dentro da Anpad, a mais expressiva organização acadêmica de Administração do Brasil.

Apesar destes avanços, ainda resta muito a fazer para que efetivamente se possa vislumbrar o potencial que a análise historicamente situada e fundamentada oferece para a pesquisa organizacional (VIZEU, 2010a), especialmente naquilo que se refere às conseqüências epistemológicas e metodológicas decorrentes da constatação de que as organizações e seu sistema de administração são um fenômeno historicamente determinado (VIZEU, 2010b). Em razão desta tarefa por fazer, o presente trabalho pretendeu ensaiar possíveis contribuições para os estudos organizacionais do método historiográfico denominado "história dos conceitos" (Begriffsgeschichte), de autoria do historiador alemão Reinhart Koselleck. Assumindo uma dimensão maior do que a pura implicação metodológica da escrita historiográfica, a Begriffsgeschichte deve ser compreendida como uma teoria da história (JASMIN, 2006; WHITE, 2002) a qual, além de situar a natureza daquilo que denominamos por 'História', também nos permite avançar na análise da própria modernidade.

Diante destes aspectos, podemos demarcar a contribuição que se pretende com a adoção da perspectiva da História dos Conceitos para os estudos organizacionais. Epistemologicamente, consideramos a significativa contribuição teórica da abordagem de Koselleck, já que a teoria da história da Begriffsgeschichte serve como arcabouço explicativo para a análise do fenômeno organizacional enquanto um dos mais importantes produtos históricos da modernidade. Na verdade, o esforço de Koselleck em desenvolver o entendimento amplo dos conceitos históricos fundamentais da era moderna também serve à compreensão das organizações modernas a partir de sua relação com outros mecanismos modernos de articulação social, tais como o Estado e a sociedade civil, temas também tratados pela história dos conceitos. Metodologicamente, a Begriffsgeschichte oferece recursos para a operacionalização de pesquisas a

Revista Brasileira de Estudos Organizacionais • v. 1. n. 2, p. 165-186, dez. 2014, eISSN: 2447-4851 Sociedade Brasileira de Estudos Organizacionais 
respeito da abrangência semântica de formas discursivas específicas dentro do pensamento organizacional, formas estas que se traduzem nos conceitos fundamentais da prática organizacional e na reflexão que os acadêmicos fazem desta.

Além da introdução, o texto está estruturado em seis partes. Primeiramente, apresentamos algumas indicações quanto às afiliações acadêmicas e teóricas do autor, feitas no sentido de revelar a trajetória intelectual de Koselleck, bem como para contextualizar o ambiente sóciohistórico de constituição da abordagem teórico-metodológica proposta por este historiador. Neste esforço, partimos do princípio sugerido por Thompson (2000) para a análise de formas simbólicas em ciências sociais, onde, para se constituir uma verdadeira análise de objetos empíricos socialmente construídos e situados - o que, no nosso caso, trata-se da teoria/metodologia da Begriffsgeschichte - se faz necessário situar o contexto social e histórico de formação destas formas simbólicas.

Nos dois subitens seguintes, apresentamos sinteticamente os fundamentos da Begriffsgeschichte, apontando os principais pontos que levam a compreender esta abordagem em sua dimensão metodológica, mas também, enquanto proposta teórica, especificamente, enquanto teoria da história e da historiografia.

Na quarta parte, tratamos de algumas das objeções feitas a proposta koselleckiana, de forma a situar as limitações e potencialidades de seu uso, especialmente, em outros campos disciplinares fora da historiografia. $\mathrm{Na}$ quinta parte, apresentamos nosso principal intento com este ensaio, que é o de tecer considerações acerca das possíveis contribuições metodológicas e teóricas da Begriffsgeschichte aos estudos organizacionais, onde destacamos dois pontos em particular. Nas considerações finais, apontamos algumas de nossas expectativas em relação a adoção da perspectiva de Koselleck dentro dos atuais esforços de renovação dos Estudos Organizacionais.

\section{Reinhard Koselleck: Afiliações intelectuais e trajetória acadêmica}

Entre os historiadores, a obra de Koselleck é considerada uma das mais respeitadas abordagens históricas, especialmente no que tange à história intelectual. Ao mesmo tempo, Koselleck também é influente nas ciências sociais - especialmente na ciência política - justamente por se propor a aproximar estes dois campos de saber (história e ciências sociais), considerados como disciplinas acadêmicas de difícil conversação (BURKE, 2000). Ao lado do chamado contextualismo lingüístico inglês, a história dos conceitos proposta e realizada por Koselleck polariza o debate a respeito da análise histórica do pensamento político e de suas representações sistemáticas na filosofia política (Jasmin, 2005). 
Devedor da tradição idealista germânica - Geisteswissenschaften - que tem origem em Hegel e Kant, Koselleck constitui seu edifício teóricometodológico a partir das concepções relativistas a cerca da produção de conhecimento e da percepção sobre a verdade/realidade. É por isso que, mesmo sendo um historiador preocupado com a escrita do passado, Koselleck procura demarcar a necessidade de se constituir uma teoria subjetivista da história, que considerasse a própria história como uma produção discursiva temporalmente situada e contextualizada em específicas relações sociais. Assim, Koselleck se afilia à tradição hermenêutica que reproduz - a partir de meados do século vinte - a guinada lingüística na filosofia e nas ciências sociais (ARAGÃO, 1997), reconhecendo a centralidade da linguagem nas interações sociais e na concepção ontológica do universo humano. Dentro do argumento de Koselleck, facilmente se reconhece a influência de importantes hermeneutas, tais como Gadamer, Ricoeur, Searle e Austin (JASMIN, 2005; WHITE, 2002).

Mesmo tendo realizado importantes e pontuais leituras historiográficas a partir de sua obra, foi na formulação e no desenvolvimento da abordagem metodológica Begriffsgeschichte que Koselleck dedicou a maior parte de sua vida acadêmica. Formulada para ser um método historiográfico - que Koselleck, junto a Werner Conze e Otto Brunner, aplicou na edição de seu célebre dicionário de conceitos germânicos, o Geschichtliche Grundbegriffe - a história dos conceitos apresenta profundas implicações teóricas e epistemológicas e, por isso, também se constitui como um importante referencial para o cientista social. Uma de suas principais contribuições é a disponibilização de recursos importantes para a interpretação da modernidade, em particular para se compreender a natureza das formas simbólicas e institucionais que caracterizam esse tempo histórico.

Não sendo um tipo exclusivista de interpretação histórica, o Begriffsgeschichte foi proposto por Koselleck para ser um método que vai além da simples preocupação filológica e etimológica dos conceitos históricos (WHITE, 2002). O método emerge da discussão de Koselleck a respeito da teoria da história, que levanta a questão de que mesmo o conceito de história tem sua própria história. Koselleck explica que somente na era moderna a ideia de história assume um caráter totalizante, que diz respeito tanto a uma continuidade diacrônica quanto à totalidade da humanidade. Neste sentido, a História (iniciada com maiúscula e no singular) emerge enquanto conceito absoluto, em substituição à concepção fragmentada que vigorava nos períodos pré-modernos - onde se narravam múltiplas histórias de eventos pontuais e desconectados, como, por exemplo, a história da guerra de Tróia, ou a história da queda de Julio Cesar. Somente com o abandono da concepção escatológica de expectativa 
futura - conseqüência da secularização da era moderna - e a noção totalizante de humanidade - constituída pelo desenvolvimento de uma concepção maniqueísta herdada da noção de cristãos e pagãos - é que se pode vislumbrar uma História única e total, em curso constante e que conecta todas as sociedades (KOSELLECK, 2002). É somente a partir desta concepção de História que foi possível se pensar em uma Teoria da História, um projeto que Koselleck pretendeu contribuir com sua discussão sobre a semântica dos tempos históricos.

\section{Begriffsgeschichte enquanto estudo semântico dos tempos históricos}

Como o próprio nome sugere, o estudo semântico dos tempos históricos é um método cujo propósito é a investigação dos atributos distintivos de cada período histórico, através da compreensão da sucessão de diferentes significados dos conceitos fundamentais de determinação da vida social. Neste sentido, Koselleck aponta que cada período histórico é marcado por uma maneira distinta de vivenciar a experiência passada, assim como também é diferente em cada tempo histórico a forma como cada sociedade manifesta sua expectativa futura. Desta relação reflexiva entre passado e futuro em cada período histórico, as sociedades conectadas, sob o ponto de vista simbólico e lingüístico, intensa ou frouxamente - vão reconstituindo a sua concepção sobre o passado, ou seja, vão modificando sua narrativa da história (Geschichte), situando-a novamente em relação à experiência do presente e, assim, redefinindo sua própria visão de futuro.

Essa concepção hermenêutica de significação do tempo histórico que conecta passado, presente e futuro em uma relação em constante mutação, além de sugerir que a verdade dos fatos históricos é linguisticamente situada, também aponta para uma dinâmica das expressões lingüísticas que é dependente dos acontecimentos concretos. Ou seja, os acontecimentos concretos - guerras, alianças, cataclismas, pestes, etc. - são experenciados pelos indivíduos de tal forma que estes redefinem suas próprias concepções lingüísticas sobre esta mesma experiência (JASMIN, 2005; KOSELLECK, 1992). Essa é a relação entre discurso e ação que Koselleck coloca no centro de seu método de investigação histórica.

O ponto central na investigação histórica proposta por meio do Begriffsgeschichte é a superação da concepção natural de tempo, subtendida na historiografia de tradição rankeana. Para Koselleck, o tempo, quando tomamos a experiência social, assume uma dimensão eminentemente diferente daquela que se estabelece no mundo natural (regido pelos eventos naturais, como as estações do ano, por exemplo).

Como afirma Jasmin, em sua apresentação a edição brasileira de um importante livro de Koselleck:

Revista Brasileira de Estudos Organizacionais • v. 1. n. 2, p. 165-186, dez. 2014, eISSN: 2447-4851 Sociedade Brasileira de Estudos Organizacionais 
O tempo, aqui, não é tomado como algo natural e evidente, mas como construção cultural que, em cada época, determina um modo específico de relacionamento entre o já conhecido e experimentado como passado e as possibilidades que se lançam ao futuro como horizonte de expectativas. Por isso mesmo, a história - considerada como o conjunto dos fatos do passado, como dimensão existencial e como concepção e conhecimento da vida, que permitem sua inteligibilidade - deve ser apreendida em sua própria historicidade, constituindo um objeto da reflexão teórica destinada a conhecer os seus limites e as suas conseqüências. (JASMIN, 2006, p. 9)

Ou seja, a história trata de um tempo que é diferente do tempo natural. Um tempo que retrata uma vida social específica, interações específicas circunscritas em um referencial semântico e cultural específico, mas que nem por isso deixa de apresentar certa unidade, aquilo que os franceses da nova história costumaram chamar de 'mentalidade' de uma época, que, dentro de uma perspectiva fenomenológica de interação social (BERGER; LUCKMANN, 1995), se constitui no cotidiano do mundo vivido e na relação deste com o conjunto de instituições sociais que sustentam uma época. Neste sentido, como afirma o próprio Koselleck, o tempo histórico "está associado à ação social e política, a homens concretos que agem e sofrem as conseqüências de ações, a suas instituições e organizações" (KOSELLECK, 2006a, p. 14).

Para Koselleck, a própria história é um dos conceitos históricos fundamentais para se compreender a natureza do tempo histórico, tendo em vista sua preocupação em relativizar a produção social - no caso, a do historiador - dentro de um contexto semântico específico, determinado por condições sociais, políticas e econômicas particulares. Neste sentido, Koselleck se aproxima do relativismo expresso na hermenêutica de Gadamer, por considerar a possibilidade do conhecimento científico da história aquela que considera a 'fusão de horizontes interpretativos' (GADAMER, 1997) das diferentes comunidades lingüísticas que se sucedem nos diferentes tempos históricos.

Para sistematizar seu método histórico, Koselleck estabelece um conjunto de definições sobre os objetos da história conceitual. Essa preocupação em especificar os elementos teóricos que possibilitam a análise histórica de conceitos relevantes na explicação dos tempos históricos, bem como na explicação da conexão diacrônica destes, são o substrato de uma teoria da história, que põem em relevo - como elemento central do método de uma possível História total da humanidade - a 
sucessão e transformação de conceitos centrais para a vida social de cada época. Como afirma Jasmin:

Por isso a necessidade de se estabelecer os conceitos que constituem os vocabulários - campos semânticos ou domínios linguísticos - dessa ou daquela linguagem política e social, relacionando o seu uso na discussão política, social e econômica com os grupos que os sustentam ou os contestam (JASMIN, 2005, p. 32).

\section{A relação entre Passado e Futuro na era Moderna}

Um importante elemento teórico da Begriffsgeschichte diz respeito às concepções sobre 'espaço de experiência' e 'horizonte de expectativa' e seu lugar na perspectiva histórica proposta por esse corpo teóricometodológico. Na verdade, essas duas categorias teóricas não podem ser entendidas sob o mesmo critério dicotômico dos conceitos antitéticos tratados pela Begriffsgeschichte; antes, se referem a duas dimensões analíticas que revelam como o passado e o futuro se expressam na experiência presente, por meio das representações semânticas que referenciam a vida social atual e que, por sua vez, é herdeira daquelas construídas pelas sociedades passadas. Koselleck ilustra essa relação entre a referência semântica do presente e do passado pela própria dualidade do olhar do historiador sobre seu objeto de estudo:

\footnotetext{
Quando o historiador mergulha no passado, ultrapassando suas próprias vivências e recordações, conduzido por perguntas, mas também por desejos, esperanças e inquietudes, ele se confronta primeiramente com vestígios, que se conservaram até hoje, e que em maior ou menor número chegaram até nós. Ao transformar esses vestígios em fontes que dão testemunho da história que deseja apreender, o historiador sempre se movimenta em dois planos. Ou ele analisa fatos que já foram anteriormente articulados na linguagem ou então, com a ajuda de hipóteses e métodos, reconstrói fatos que ainda não chegaram a ser articulados, mas que ele revela a partir desses vestígios. No primeiro caso, os conceitos tradicionais da linguagem das fontes servem-lhe de acesso heurístico para compreender a realidade passada. No segundo, o historiador serve-se de conceitos formados e definidos posteriormente, isto é, de categorias científicas que são empregadas sem que sua existência nas fontes possa ser provada (KOSELLECK, 2006a, p. 305).
} 
Essa dualidade de planos nos quais o historiador trabalha, de acordo com Koselleck, é a mesma dualidade que cada sociedade se serve, em seu tempo, para enfrentar o desafio de compreender o presente a partir das referências do passado e das expectativas de um futuro inacabado e, em grande medida, incerto. Como já dissemos, para Koselleck (2006a), o futuro provável somente foi vislumbrado na era moderna, quando se abandonaram a visão escatológica do apocalipse bíblico. A implicação desta nova orientação sobre o futuro é o descolamento entre o futuro e o presente, ou seja, não há mais um mesmo futuro para a humanidade (o juízo final), mas diferentes futuros, que se constituem sucessivamente a cada novo passo dentro do tempo histórico.

Para dar conta deste relativismo no âmbito do horizonte de expectativas, é preciso se considerar a História como sendo uma trajetória única, um único processo pelo qual passa toda a humanidade Todavia, isso não significa dizer que a concepção deste processo seja objetivista, onde se toma o conhecimento sobre esse processo como algo acabado e definitivo; na verdade, a cada nova experiência presente, se reconstitui a expectativa do futuro e as leituras que se faz do passado, com novas referências semânticas para representar a continuidade entre passado, presente e futuro. Essa é a dimensão diacrônica que Koselleck (2002) observa como ordenadora da análise dos conceitos históricos, a base da construção do saber historiográfico da Begriffsgeschichte.

\section{O conceito de conceito}

A relação entre linguagem e sociedade tem sido alvo de discussões teóricas em diversas áreas do conhecimento, incluindo-se a Filosofia da Linguagem, a Psicologia Cognitiva, a Lingüística, dentre outras. No contexto da Begriffsgeschichte, o papel da linguagem assume uma posição central na construção do conhecimento fundamentado em análises historiográficas. A história conceitual, portanto, trata-se de um tipo de estudo da linguagem, cuja unidade de análise constitui-se de uma espécie de signo lingüístico em particular: o conceito.

A noção de conceito, em Koselleck, indica um termo cuja principal característica é a representação simultânea de múltiplos significados relacionados a períodos de transição histórica, em especial, daquela promovida dentro da modernidade burguesa. Essa polissemia permite que esses conceitos carreguem ao mesmo tempo - e em um determinado presente - significados do passado e horizontes de expectativas para o futuro.

Os conceitos que constituem o foco de interesse da Begriffsgeschichte são de natureza política e social, e permitem a apreensão retrospectiva das chamadas camadas de significado. Esquematicamente, esses conceitos 
correspondem a significados 'verticais', tomados a partir da análise de períodos históricos específicos, ao mesmo tempo em que correspondem a significados 'horizontais', tomados a partir da análise transversal da história desse mesmo conceito (Figura 1).

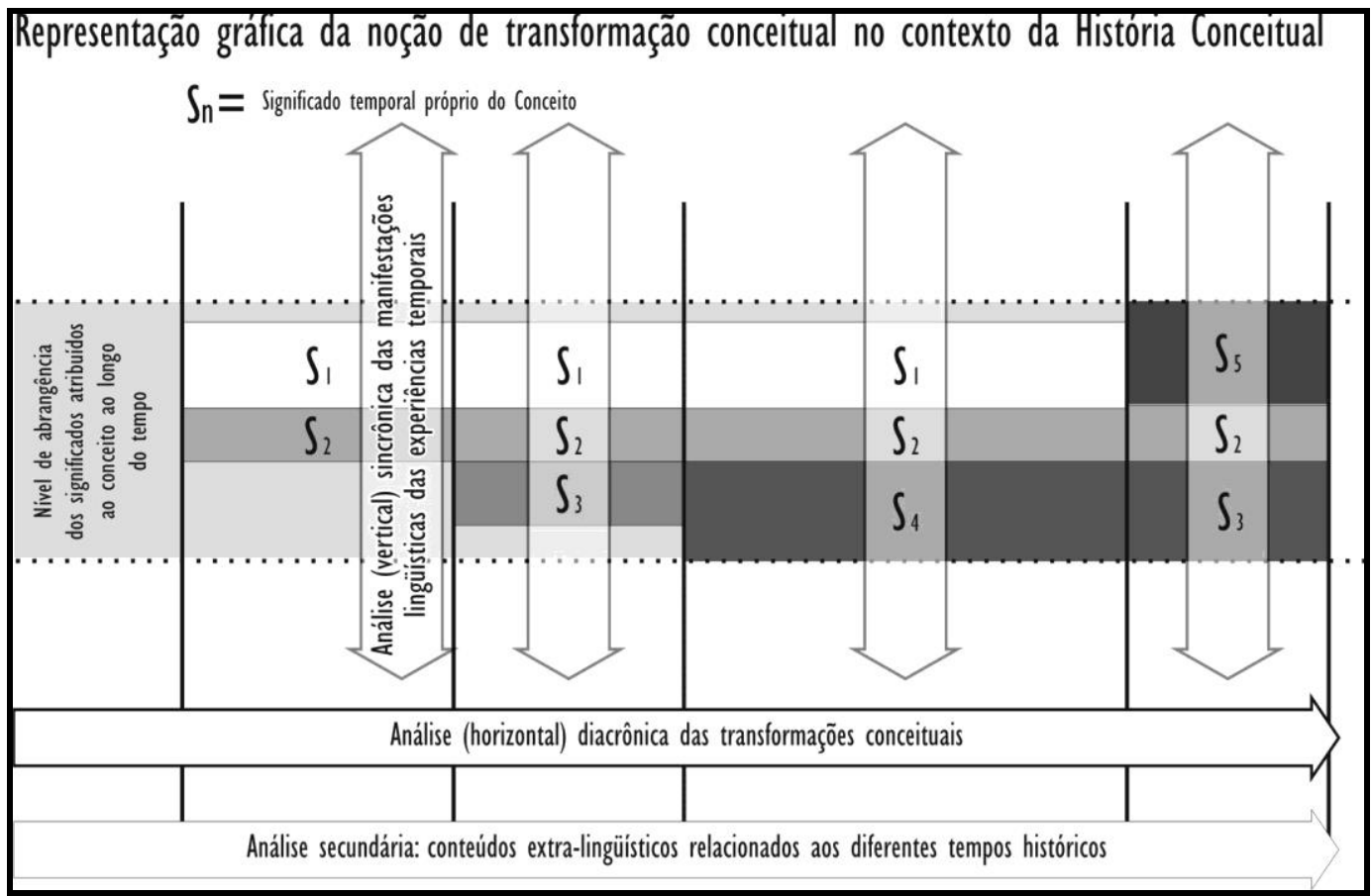

Fonte: Os autores.

Nas palavras de Koselleck (2006a, p.16): “No que diz respeito à metodologia, as investigações concentram-se na [análise] semântica dos conceitos fundamentais que plasmaram a experiência histórica do tempo.". O estudo desses conceitos pretende revelar - por meio da compreensão dos seus significados sincrônicos e diacrônicos - a forma como o mundo moderno tomou consciência de sua própria condição de modernidade, além de desvelar significados criados e não concretizados no período moderno. Ou seja, a análise conceitual proposta pela Begriffsgeschichte pretende indicar horizontes de expectativa de futuro contidos nos significados de conceitos do passado. Acredita-se, portanto, que conceitos político-sociais servem aos propósitos de significação, resignificação e invenção das experiências vividas no passado e das expectativas de futuro. Dessa forma, a linguagem se torna ao mesmo tempo um indicador e um agente de mudanças sociais, além de um campo de batalhas semânticas que buscam definir, manter ou impor posições 
políticas e sociais. Ao ilustrar um exemplo de transformação conceitual, Jasmin (2006, p. 11) explica que:

Se as histórias (no plural) guardavam a sabedoria acumulada pelos exemplos do passado para servir de guia à conduta presente, evitando a repetição dos erros e estimulando a reprodução do sucesso, a História (como um singular coletivo) tornou-se uma dimensão inescapável do próprio devir, obrigando toda ação social a assumir horizontes de expectativa futura que a inscrevam como um desdobramento consoante com o processo temporal. Não se trata tão-somente de uma alteração nos significados tradicionais, mas de uma verdadeira revolução nas maneiras de conceber a vida em geral, de imaginar o que nela é possível ou não, assim como o que dela se deve esperar.

Consequentemente, a metodologia da Begriffsgeschichte - embora inclua a pesquisa etimológica e filológica dos conceitos - vai além dessas ao propor um estudo da consciência humana a respeito das suas realidades e possibilidades existenciais.

Tipos de conceitos e origem dos vocábulos

Há basicamente duas origens dos conceitos estudados no âmbito da Begriffsgeschichte: a das fontes (textos originais) e a científica. No primeiro caso, o objetivo é a tradução contemporânea dos conceitos do passado. No segundo, a verificação da capacidade de rendimento das definições contemporâneas de conceitos científicos. Ou seja, a aplicação de conceitos definidos ex post na análise de fenômenos anteriores a essas definições.

Os textos selecionados para a aplicação do método são aqueles nos quais a experiência temporal se manifesta na linguagem, de maneira explícita ou implícita. Ou seja, devem ser textos que "abordam a relação entre um determinado passado e um determinado futuro" (KOSELLECK, 2006a, p.15). Aqui incluem-se, por exemplo, enciclopédias, textos políticos, filosóficos e teológicos, poesias e provérbios. Ao contrário da história social, que utiliza os textos e vocábulos para deduzir a partir deles fatos e dinâmicas externos ao próprio texto, a história conceitual conduz um tipo de exegese textual cujo objetivo é decifrar os significados dos conceitos políticos e sociais presentes nos textos selecionados para tal finalidade. Para tanto, a Begriffsgeschichte busca identificar os momentos de duração, alteração e futuridade contidos na realização lingüística de determinada situação concreta. Ressalte-se, ainda, que, nesse caso, o estudo paralelo do contexto histórico, econômico, legal, social e político que une emissor e 
receptor - como aquele proposto por Gadamer (1997) - é uma condição para a interpretação, e não a finalidade da mesma.

Quanto ao aspecto temporal, os conceitos políticos e sociais de interesse da Begriffsgeschichte podem ser divididos em três grupos (RICHTER, 2006; JASMIN, 2006). Alguns conceitos, tais como democracia, podem ser considerados sob esses três aspectos:

(i) Os conceitos tradicionais da doutrina constitucional aristotélica, cujos significados lexicais são parcialmente permanentes. Ou seja, conceitos de longo uso cujo significado pode ainda ser alcançado e compreendido pelos que falam a língua hoje;

(ii) Os conceitos cujo significado se alterou decisivamente ao longo do tempo, tais como "classe" ou "história". Esses conceitos só podem ser compreendidos após uma reconstrução erudita de seus significados anteriores;

(iii)Os neologismos, os quais surgem em determinados momentos como reação a determinadas situações sociais ou políticas cujo ineditismo procuram registrar ou até mesmo provocar, tais como "conservadorismo", "liberalismo" ou "socialismo". São conceitos criados durante as mesmas interpretações revolucionárias que ajudaram a formar ou interpretar.

Quando estudados aos pares, surgem os denominados conceitos assimétricos antitéticos. Estes são conceitos binários que pretendem incluir universalmente todas as pessoas, criando um fenômeno de inclusão daqueles que reclamam para si o direito de uso exclusivo de um conceito lingüístico - e de exclusão - daqueles que não fazem parte de determinada unidade de ação política e social - polis, povo, partido, classe, etc. São exemplos de conceitos assimétricos antitéticos já estudados no contexto da Begriffsgeschichte: "helenos e bárbaros", "cristãos e pagãos", "homem e não-homem": "O que caracteriza os conceitos antitéticos desiguais é que eles determinam uma posição seguindo critérios tais que a posição adversária, deles resultante, só pode ser recusada. Nisto reside sua eficácia política..." (KOSELLECK, 2006a, p.195).

Principais características dos conceitos no contexto da Begriffsgeschichte 
Segue uma síntese das principais características dos conceitos no contexto da Begriffsgeschichte. Em primeiro lugar, o conceito não é apenas um reflexo de uma realidade. É um indicador (no presente) de uma posição política ou social que reflete um passado e sinaliza um (novo) futuro. Em outras palavras, correspondência não é sinônimo de identidade.

Além disso, "Todo conceito se prende a uma palavra, mas nem toda palavra é um conceito social e político" (KOSELLECK, 2006a, p.108). Ou seja, conceitos sociais e políticos são necessariamente polissêmicos e generalizantes em termos das experiências e expectativas que podem abranger em termos de significação. $O$ uso lingüístico do conceito pressupõe, portanto, a manutenção dos múltiplos significados associados ao conceito. Em outras palavras, os conceitos são vocábulos nos quais se concentra uma multiplicidade de significados.

Conceitos podem variar na extensão de conteúdo empírico que carregam. Ou seja, quanto maior o significado relacionado a uma realização futura, ou seja, quando maior o campo de expectativa ao qual faz referência, menor o conteúdo empírico presente. Os conceitos também podem variar entre si quanto à sua capacidade de ampliação em termos da quantidade de significados que podem carregar ou, ainda, da abrangência das experiências às quais fazem referência. Especialmente a partir da modernidade, de acordo com Koselleck (2006b, p.99), a maior interligação comunicativa ao redor do mundo tem causado maior abstração dos conceitos, afastando-os da experiência direta: “Os conceitos tornam-se necessariamente mais abstratos, ao mesmo tempo mais gerais e menos descritivos que nunca".

A identificação e análise de conceitos-chave pode (e deve) seguir dois caminhos: o semasiológico - relacionando a palavra aos seus significados - e onomasiológico - relacionando diferentes designações para um mesmo fato ou para fatos semelhantes. Nesse contexto, é importante também a identificação de conceitos paralelos e conceitos antônimos que ajudem a explicar outras dimensões ou aspectos do mesmo fenômeno. Finalmente, cada conceito possui um campo semântico, formado por conceitos complementares ou paralelos que contribuem para formar um campo de significado.

\section{Críticas e objeções à história dos conceitos}

As principais críticas à Begriffsgeschichte foram formuladas por autores anglófonos da chamada abordagem collingwoodiana para o estudo da

Revista Brasileira de Estudos Organizacionais • v. 1. n. 2, p. 165-186, dez. 2014, eISSN: 2447-4851 
história do pensamento político, anteriormente denominada Escola de Cambridge. Quentin Skinner, principal representante dessa vertente, em um primeiro contato com a Begriffsgeschichte defendeu a impossibilidade de se fazer uma história conceitual, com base em um argumento historicista radical de que um conceito é sempre único em termos espaciais e temporais. Entretanto, mais tarde Skinner revisou sua posição inicial e passou a classificar o seu próprio trabalho como uma forma de história conceitual. Já outro signatário da escola de Cambridge, John G. A. Pocock, continuou defendendo o uso do estudo sincrônico da linguagem tal como é proposto pela abordagem anglófona -, em detrimento da proposta de estudo diacrônico da Begriffsgeschichte.

Alguns autores têm proposto uma aproximação maior entre a abordagem collingwoodiana e a Begriffsgeschichte, com destaque para Melvin Richter, cientista político norte-americano responsável pela aproximação intelectual entre as duas perspectivas e figura-chave da recepção da Begriffsgeschichte em ambientes acadêmicos não-germânicos. $\mathrm{O}$ objetivo é caminhar em direção a uma síntese na qual a tradição inglesa passaria a ter um foco mais estrito na linguagem, enquanto a tradição alemã adotaria uma preocupação maior com formações lingüísticas mais complexas que sua unidade de análise atual, o conceito (JASMIN; FARES JÚNIOR, 2006).

\section{Por uma agenda de pesquisa em EOR à luz do Begriffsgeschichte}

Após apresentarmos de forma breve os fundamentos da perspectiva teórico-metodológica de Kosellleck, estamos habilitados para pensar nas possíveis contribuições que a Begriffsgeschichte oferece aos estudos organizacionais. Em um primeiro momento, é preciso lembrar que este campo acadêmico se insere dentro de uma tradição a-histórica (BOOTH; ROWLINSON, 2006; VIZEU, 2010A; COSTA; MARTINS, 2009), e que a simples adoção de uma perspectiva social que busca a compreensão da modernidade em sua historicidade já é, em si mesmo, uma medida com grandes possibilidades de avanço na produção do conhecimento sobre a realidade organizacional; todavia, desejamos pontuar de forma mais específica qual o potencial esperado da Begriffsgeschichte em sua aplicação aos estudos organizacionais, principalmente no que tange à formulação de critérios para o estabelecimento de uma agenda de pesquisa com base nesta metodologia. Assim, apresentamos dois direcionamentos que visam sinalizar este caminho. 
Begriffsgeschichte como fonte de conhecimento para a compreensão da realidade organizacional

Tendo em conta que o arcabouço historiográfico da Begriffsgeschichte é, em grande medida, uma leitura sobre a constituição da modernidade, feita a partir da emergência e transformação de conceitos fundamentais na organização da vida social e política, o pesquisador/teórico das organizações poderá compreender melhor seu objeto de investigação que, em essência, é uma das mais importantes marcas da modernidade - a partir da compreensão deste desenvolvimento semântico apresentado pela obra de Koselleck e seus colaboradores. Como sugere Jasmin:

Ao investigar o que é manifesto pela linguagem, [Koselleck] pretendeu também compreender os modos pelos quais o mundo moderno tomou consciência de sua(s) própria(s) modernidade(s), orientando a pesquisa histórica para o pensamento do mundo contemporâneo e indagando em que medida estamos ou não, ainda hoje, experimentando o mesmo universo de significados. (JASMIN, 2006, p. 10)

Richter (2006, p.39), reforça essa posição ao afirmar que o Geschichtliche Grundbegriffe (o dicionário editado por Koselleck sobre os conceitos históricos fundamentais da língua política e social na Alemanha) está “...entre aquelas obras clássicas indispensáveis, consultadas preliminarmente por quem quer que esteja iniciando uma pesquisa séria sobre os temas cobertos pela área." Entre os cerca de 120 conceitos abordados nessa obra de referência da Begriffsgeschichte, incluem-se: democracia, ideologia, sistema, estrutura, organismo, crise, burocracia, para citar apenas algumas das representações lingüísticas dos fenômenos que caracterizam a modernidade e que são largamente utilizadas na literatura organizacional.

\section{Begriffsgeschichte como método para conceitos da Teoria Organizacional}

A teoria histórica de Koselleck nasce da consciência crítica de que há uma lacuna entre os eventos históricos e a linguagem utilizada para representá-los. Há, portanto, nos discursos sobre o passado, um elemento de representação lingüística que ultrapassa os limites da simples tradução e que exige um cuidado especial por parte dos usuários do conhecimento histórico. Portanto, qualquer produção de conhecimento que esteja fundamentada no passado precisa levar em consideração a interferência da linguagem sobre a representação da história. Ou seja, é preciso 
compreender as implicações lingüísticas da linguagem utilizada no passado e, ao mesmo tempo, é preciso adequar a linguagem utilizada no presente para representar esse mesmo passado.

Também se deve considerar que o método proposto pela Begriffsgeschichte é adequado ao mapeamento de conceitos que constituem vocabulários especializados, ou seja, ao estudo dos campos semânticos ou territórios lingüísticos de um determinado tipo de linguagem utilizada por determinado grupo social (RICHTER, 2006). Neste sentido, a Begriffsgeschichte é uma ferramenta importante na prevenção do anacronismo, ou seja, da falta de alinhamento entre uma interpretação atual e um significado tal como foi originalmente formulado no passado. E, ainda, serve como base para estudos históricos comparativos dos usos nacionais de conceitos políticos e sociais: "Para Richter, o problema da tradução, e todas as questões de ordem prática e metodológica que ele suscita, torna-se crucial para pensar a história conceitual de maneira comparada e também para se estudar a recepção de conceitos em países que foram colonizados no passado." (JASMIN; FARES JÚNIOR, 2006, p.34). Como este é o caso do Brasil, a análise lingüística da história dos conceitos representa uma saída para a maneira como se processou (e ainda se processa) a importação semântica de antigos colonizadores.

E, apesar de ter sido desenvolvida originalmente para o estudo de um período específico - o Sattelzeit, período de transição entre o início da modernidade e a modernidade propriamente dita na Alemanha, e que abrange os anos de 1750 a 1850, aproximadamente - a Begriffsgeschichte originou-se de uma intuição que permite sua aplicação a outros contextos históricos, atendendo à sensação da "aceleração" do tempo durante os períodos de transição (MOTZKIN, 2006). Essa percepção de aceleração se reflete em mudanças de sentido conceitual não apenas no sentido semântico, mas também temporais. Ou seja, um conceito tem um senso de temporalidade variável, podendo referir-se a períodos de tempo mais longos ou mais curtos, e também a diferentes densidades em termos da experiência ao qual fazem referência. A implicação dessa noção implícita na Begriffsgeschichte é que o método proposto por Koselleck não precisa ficar restrito ao estudo do período para o qual foi desenvolvido originalmente. É possível identificar outros períodos históricos incluindo-se períodos mais recentes - onde foi possível perceber uma sensação de aceleração do tempo, seja do ponto de vista da extensão ou da intensidade temporal. Nesse sentido, cabe aos pesquisadores da área de Estudos Organizacionais identificar conceitos próprios da área - e também conceitos importados de outras áreas (WHETTEN; FELIN; KING, 2009) com essa capacidade de indicarem períodos de tempo passados, evocarem momentos decisivos, projetarem futuros, e até mesmo chamarem a um determinado tipo de ação. Esses conceitos são particularmente 
importantes porque afetam o mundo extra-conceitual ou extra-lingüístico, provocando mudanças na maneira de entender o passado e de construir o futuro.

Outra questão, mencionada por Feres Júnior (2007), merece destaque: a apropriação de conceitos da linguagem comum pelos discursos especializados das ciências sociais. Ou seja, esses conceitos podem sofrer variações semânticas ao serem incorporados e utilizados em modalidades técnicas de discurso das ciências humanas e sociais. Essas variações merecem investigações principalmente porque podem desvelar diferentes horizontes temporais relacionados aos conceitos, diferentes modalidades de ação justificadas pelo uso desses conceitos e, ainda, variações causadas pela apropriação científica na abrangência de significado de cada conceito.

\section{Limitações de uso da Begriffsgeschichte em Estudos Organizacionais}

A objeção que se pode fazer a aplicação do método de história dos conceitos aos conceitos pertencentes aos estudos organizacionais - como, por exemplo, os conceitos de cultural organizacional e de comportamento organizacional - se refere a concepção de tempo longo subentendida na noção de tempo histórico de Koselleck. Neste ponto, Koselleck considera o tempo histórico como uma totalidade que só pode ser observada no longo prazo, e essa condição caracteriza sua medida de época. O interesse da história dos conceitos pela transposição diacrônica de significados ao longo das eras, por um lado, e pela sincronia destes dentro de cada uma em particular, por outro, se revela somente quando se observa a totalidade de um tempo histórico, tempo este semanticamente homogêneo dentro da totalidade da era, mas que também apresenta uma singularidade, se comparado a outros períodos.

Assim, como pensar em mudança histórica de conceitos engendrados na teoria organizacional se esta se constitui em uma história breve, em um curto capítulo dentro da modernidade (WAHRLICH, 1986)? Será que é possível aplicar a noção de diacronia em períodos tão diminutos como aqueles que marcaram as mudanças semânticas dentro da breve história do mundo das organizações modernas, tão breves que talvez não expressem nenhuma mudança de tempo histórico, mas tão somente, a heterogeneidade natural que se manifesta nas complexas relações multiculturais da modernidade, traduzidas pela polifonia semântica tão característica de nosso tempo (HABERMAS, 2002)?

A essa objeção, podemos apresentar a própria percepção do autor de que a duração de tempo longo - tão significativa na determinação do momento de mudança nas eras pré-modernas - se torna cada vez menos presente no mundo moderno. Koselleck considera que as instituições que sustentam a vida moderna modificaram o ritmo da História, 
possibilitando a sucessão de novos ciclos de forma muito mais rápida. Como afirma o historiador:

\begin{abstract}
...se no cômputo da experiência subjetiva, o futuro parece pesar aos contemporâneos por ele afetados, é porque um mundo técnica e industrialmente formatado concede ao homem períodos de tempo cada vez mais breves para que ele possa assimilar novas experiências, adaptando-se assim a alterações que se dão de maneira cada vez mais rápida (KOSELLECK, 2006, p. 16).
\end{abstract}

É claro que esta percepção de Koselleck sobre o ritmo acelerado das mudanças na modernidade não elimina a necessidade de se ater a longa duração na compreensão dos ciclos históricos; entretanto, não foi preocupação deste historiador alemão compreender a dinâmica interna da própria modernidade, apesar dele reconhecer que, neste período, há uma multiplicidade de momentos, dados pela intensidade da experiência social e pelo subseqüente dinamismo que desta experiência deriva.

Ou seja, podemos pensar que, dentro da modernidade, onde as mudanças sociais são mais intensas, também se verifica alterações nas referências semânticas vinculadas a estas mudanças. Um bom argumento que se pode apresentar para esta ideia é a grande quantidade de neologismos que se sucedem na vida política e social nas últimas décadas, ou mesmo a constante re-significação de termos e expressões que, em razão das intensas transformações sociais que tiveram lugar no século $X X$, se manifesta como novas concepções da vida social e reflete momentos históricos que, para a contemporaneidade, são estranhos. É por isso que entendemos ser possível se pensar em uma história dos conceitos do corpo de conhecimento organizacional, pois é sabido que, mesmo em se tratando de um fenômeno muito recente (cerca de um século), as organizações modernas apresentam uma dinâmica semântica que exige do pesquisador certo cuidado para não incorrer em anacronismo (JACQUES, 2006).

Por exemplo, será correto se pensar que o conceito atribuído a palavra 'organização', tal qual ele foi expresso pelos autores clássicos do Management (Taylor, Ford, Fayol, Gulick, Gilbreth, Urwick, etc), é o mesmo assumido pelos sociólogos funcionalistas que inauguraram a teoria das organizações algumas décadas depois? Se tivermos em conta que, neste breve período, o fenômeno organizacional se modificou drasticamente em quantidade e qualidade, bem como a realidade política e social - basta lembrar das duas grandes guerras que ocorreram entre estes dois períodos - é possível supor que não se trata do mesmo conceito. De certo, mesmo sem assumir os pressupostos analíticos propostos por Koselleck, muitos revisores do pensamento organizacional já alertaram 
para as diferentes concepções sobre 'organização' entre os grupos de autores que viveram em diferentes períodos (por exemplo, WAHRLICH, 1986).

\section{Considerações finais}

Ao apresentar a Begriffsgeschichte como um importante método para a área de estudos organizacionais, além de estarmos reivindicando que se adote neste campo acadêmico perspectivas teórico-metodológicas capazes de superar a limitada visão a-histórica sobre a realidade social que a herança do funcionalismo sociológico nos impingiu (VIZEU, 2010a), também estamos interessados em sistematizar um possível programa de pesquisa diretamente relacionado com a produção de estudos preocupados com a historicização do fenômeno das organizações (BOOTH; ROWLINSON, 2006). Esse programa, traduzindo-se empiricamente com a leitura historiográfica da análise organizacional, também se fundamentaria na preocupação com a questão dos conceitos em estudos organizacionais, algo que já foi observado como importante para a compreensão da própria formação do pensamento organizacional seja este acadêmico ou profissional - mas também, do entendimento dos mecanismos sociais nos quais a produção deste conhecimento se estabelece (MATITZ; VIZEU, 2010).

Todavia, não negamos que tal intento se insere dentro de um esforço que já vem sendo emprendido na área, especialmente na Europa e mesmo no Brasil. A ampliação do quadro teórico-metodológico de que se serve o pesquisador das organizações a partir do empréstimo de outros campos disciplinares vem ocorrendo há certo tempo, mesmo que nem sempre com o cuidado de se preservar a consistência epistemológica que tais formulações abarcam em suas áreas de origem (WHETTEN; FELIN; KING, 2009). Contudo, especialmente nas disciplinas acadêmicas conhecidas dentro do rótulo de 'humanidades' - como é o caso da história - ainda se percebe potencial para se descortinar novas formas de investigar o fenômeno das organizações (ZALD, 1993), tendo em vista a ainda forte presença dentro dos estudos organizacionais de uma concepção positivista de ciência na maneira como se investiga a realidade social (VIZEU, 2010a). Assim, mesmo tendo apresentado pontualmente uma agenda de pesquisa para a adoção da história dos conceitos de Koselleck nos estudos organizacionais, esse esforço ainda está por se fazer, constituindo-se nossa tentativa apenas como uma proposição inicial.

A grande contribuição teórica da Begriffsgeschichte para os estudos organizacionais diz respeito ao seu entendimento sobre a História e a sociedade moderna. Neste último ponto, uma interessante contribuição é se pensar o fenômeno das organizações a partir do que Koselleck

Revista Brasileira de Estudos Organizacionais • v. 1. n. 2, p. 165-186, dez. 2014, eISSN: 2447-4851 Sociedade Brasileira de Estudos Organizacionais 
identificou como o descolamento entre a experiência passada e o horizonte de perspectiva futura que se processo na era moderna. Como afirma Koselleck (2002), as sociedades pré-modernas se constituem a partir da concepção de um futuro escatológico e sua leitura sobre o passado se traduz em uma narrativa de época fundada na expectativa deste devir fatalista. Na era moderna, a concepção de futuro se torna aberta, e se constituem explicações sobre uma marcha da História onde se busca vislumbrar expectativas prováveis sobre o futuro.

Consideramos em nosso ensaio que as organizações enquanto entidades históricas modernas refletem essa mesma expectativa, e a vida organizacional se traduz a partir da reconstrução de um futuro incerto. $\mathrm{Ou}$ seja, no âmbito das organizações, prováveis expectativas vão se reconstruindo a medida que nossa leitura semântica e teórica sobre a vida organizacional vai se modificando. Essa fluidez semântica no interior da vida organizacional pode ser observada especialmente pelo intenso debate sobre temas e conceitos e sua dinâmica ao longo dos anos; também observamos que há um significativo esforço de renovação conceitual e construção de neologismos que refletem esse processo (WHETTEN; FELIN; KING, 2009). Assim sendo, acreditamos ser o principal papel dos Estudos Organizacionais assumir uma perspectiva consciente e crítica sobre seu conhecimento, o que pode ser obtido com a ajuda dos elementos teóricos da Begriffsgeschichte.

Tendo em conta os limites do presente texto em se tratando este de uma primeira aproximação entre a Begriffsgeschichte e os Estudos Organizacionais, sugerimos alguns pontos orientadores de pesquisas futuras. Estes se constituem como tarefas preliminares para a solução de certos dilemas sobre a possibilidade de uso e as efetivas contribuições da abordagem histórica koselleckiana que se ensaiaram aqui, de forma ainda embrionária: como dar conta, em um programa de pesquisa baseado na Begriffsgeschichte, da construção polissêmica de conceitos praticada na área? Como situar o problema da tradução livre feita pelos autores de textos acadêmicos de termos originados em línguas estrangeiras, tradução esta nem sempre coincidente com as aquelas advindas de outras fontes (como a mídia, por exemplo) e que também são referenciadas pela literatura acadêmica especializada? Como programar um conjunto de conceitos da área relevantes de serem investigado a luz da Begriffsgeschichte? Quais as fontes disponíveis para empreender uma análise diacrônica de conceitos em Estudos Organizacionais de forma a se conformar aos critérios apresentados pelos historiadores afiliados à perspectiva koselleckiana (dicionários, textos clássicos, mídia, etc.)?

Finalmente, esperamos que nosso texto sirva de inspiração para que outros pesquisadores se interessem por conhecer mais a fundo a obra de Koselleck. De natureza densa e nem sempre de fácil compreensão, a 
Begriffsgeschichte exige de seus signatários um grande preparo, bem como a sua adoção em projetos de pesquisa empírica também se configura como um intento que exige grande dedicação; entretanto, como aqui foi observado, não se pode negar que esta perspectiva teórico-metodológica prove ao pesquisador organizacional uma frutífera contribuição, dada pela melhor compreensão da vida social e da semântica moderna e pelo amadurecimento reflexivo e analítico da realidade organizacional.

\section{Referências}

ARAGÃO, L. M. de C. Razão comunicativa e teoria social crítica em Jürgen Habermas. 2. ed. Rio de Janeiro: Tempo Brasileiro, 1997.

BERGER, P.; LUCKMANN, T. A construção social da realidade: tratado de sociologia do conhecimento. 12. ed. Petrópolis: Vozes, 1995.

BOOTH, C.; ROWLINSON, M. Management and organizational history: prospects. Management \& Organizational History, v. 1, n. 1, p. 5-30, 2006.

BURKE, P. History and social theory. 2. ed. New York: Cornell University Press, 2005.

COSTA, A. M.; BARROS, D. F.; MARTINS, P. E. M. Perspectiva Histórica em Administração: Panorama da Literatura, Limites e Possibilidades. Encontro da Associação Nacional de Pós-Graduação e Pesquisa em Administração, 33, 2009. Anais... São Paulo: ANPAD, 2009.

FERES JÚNIOR, JOÃO. Para uma história conceitual crítica do Brasil: recebendo a Begriffsgeschichte. In: FERES JÚNIOR, J.; JASMIN, M. G. História dos conceitos: diálogos transatlânticos. Rio de Janeiro: Ed. PUCRio: Ed. Loyola: IUPERJ, 2007, p.109-118.

GADAMER, H. G. Verdade e método, vol. I. Petrópolis: Vozes, 1997.

HABERMAS, J. A inclusão do outro: estudos de teoria política. São Paulo: Loyola, 2002.

JACQUES, R. S. History, historiography and organization studies: the challenge and the potential. Management \& Organizational History, v. 1, n. 1, p. 31-49, 2006.

JASMIN, M. G. História dos conceitos e teoria política e social: referências preliminares. Revista Brasileira de Ciências Sociais, v. 20, n. 57, p. 27-38, 2005.

Revista Brasileira de Estudos Organizacionais • v. 1. n. 2, p. 165-186, dez. 2014, eISSN: 2447-4851 Sociedade Brasileira de Estudos Organizacionais 
JASMIN, M. G. Apresentação. In: KOSELLECK, R. Futuro Passado: contribuição à semântica dos tempos históricos. Rio de Janeiro: Contraponto/ Ed. PUC-Rio, p. 9-12, 2006.

JASMIN, M.G.; FERES JÚNIOR, J. (orgs). História dos Conceitos: debates e perspectivas. Rio de Janeiro: Edições Loyola, IUPERJ, 2006.

KOSELLECK, R. Uma história dos conceitos: problemas teóricos e práticos. Estudos Históricos, v. 5, n. 10, p. 134-146, 1992.

KOSELLECK, R. The practice of conceptual history: timing history, spacing concepts. Stanford: Stanford University Press, 2002.

KOSELLECK, R. Futuro Passado: contribuição à semântica dos tempos históricos. Rio de Janeiro: Contraponto/ Ed. PUC-Rio, $2006 a$.

KOSELLECK, R. Uma resposta aos comentários sobre o Geschichtliche Grundbegriffe. In: JASMIN, M.G.; FERES JÚNIOR, J. (orgs). (2006). História dos Conceitos: debates e perspectivas. Rio de Janeiro: Edições Loyola, IUPERJ, 2006, 2006b, p. 97-109.

MATITZ, Q. R.; VIZEU, F. Construção e uso de conceitos em estudos organizacionais: por uma perspectiva social e histórica. Encontro da Associação Nacional de Pós-Graduação e Pesquisa em Administração, 34, 2010. Anais... Rio de Janeiro: ANPAD, 2010.

MOTZKIN, G. A intuição de Koselleck acerca do tempo na história. In: JASMIN, M.G.; FERES JÚNIOR, J. (orgs). História dos Conceitos: debates e perspectivas. Rio de Janeiro: Edições Loyola, IUPERJ, 2006, p. 77-82.

RICHTER, M. (2006). Avaliando um clássico contemporâneo: a Geschichtliche Grundbegriffe e a atividade acadêmica futura. In: JASMIN, M.G.; FERES JÚNIOR, J. (orgs). História dos Conceitos: debates e perspectivas. Rio de Janeiro: Edições Loyola, IUPERJ, 2006, p. 39-54.

THOMPSON, J. B. Ideologia e cultura moderna: teoria social critica na era dos meios de comunicação de massa. 5. ed. Petrópolis: Vozes, 2000.

VIZEU, F. Em Algum lugar do Passado: Contribuições da Pesquisa Histórica para os Estudos Organizacionais Brasileiros. Encontro da Associação Nacional de Pós-Graduação e Pesquisa em Administração, 31, 2007. Anais... Rio de Janeiro: ANPAD, 2007. 
VIZEU, F. Potencialidades da análise histórica nos estudos organizacionais brasileiros. Revista de Administração de Empresas, v. 50, n. 1, p. 36-46, 2010a.

VIZEU, F. (Re)contando a Velha História: Reflexões sobre a Gênese do Management. Revista de Administração Contemporânea, v. 14, n. 5, 780797, 2010b.

WAHRLICH, B. S. Uma análise das teorias de organização. 5. ed. Rio de Janeiro: FGV, 1986.

WHETTEN, D. A.; FELIN, T.; KING, B. G. The practice of theory borrowing in organizational studies: current issues and future directions. Journal of Management, v. 35, n. 3, p. 537-563, 2009.

WHITE, H. Foreword. In: KOSELLECK, R. The practice of conceptual history: timing history, spacing concepts. Stanford: Stanford University Press, 2002.

ZALD, M. Organization studies as a scientific and humanistic enterprise: Towards a reconceptualization of the foundations of the field. Organization Science, v. 4, p. 513-528, 1993. 